\title{
Repository of Instructional and Assessment Techniques for OBE-based Instructional Module Development system
}

\author{
Srividya K. Bansal ${ }^{1}$, Odesma Dalrymple ${ }^{2}$ \\ ${ }^{1}$ School of Computing,Informatics, and Decision SystemsEngineering, Arizona State University, Mesa, TX, USA \\ ${ }^{2}$ Shiley-Marcos School of Engineering, University of San Diego, San Diego, CA, USA \\ 'srividya.bansal@asu.edu \\ ºdesma@sandiego.edu
}

\begin{abstract}
Instructional Module Development System (IMODS) project IMODS) project aims to assist educators in developing a STEM-based curriculum, even if the educator has not had extensive or formal training in educational methods. Research shows that choice of appropriate curriculum and assessment methods are critical in successfully teaching students and having the students retain the information taught. The IMODS strives to be a tool to assist educators in building that curriculum which will include an instructional and assessment plan. To successfully achieve this goal, a variety of educational, instructional, and assessment strategies are required to be integrated into the program. In this paper, we present the design and implementation of a repository of current best pedagogical and assessment practices that will be part of IMODS. We also present integration of this repository into the IMODS software to present options for assessment and instruction that align with the type/level of student learning desired based on selections the user makes when defining the learning objectives of the course.
\end{abstract}

Keywords: Instruction design, Outcome-based Education, Instructional \& Assessment Techniques, Semantic web-based software tool

\section{Srividya K. Bansal}

School of Computing,Informatics, a nd Decision Systems Engineering, Arizona State University, Mesa, TX, USA srividya.bansal@asu.edu

\section{Introduction}

The interest in teaching Science, Technology, Engineering, and Mathematics topics, also known as STEM, has greatly increased in the last several years. There has been a greater and greater push towards educating students in these topics from many different sources, such as governmental programs, after school programs, private corporation incentives and even within the curriculum of the schools themselves. The Instructional Module Development System (IMODS) is open-source web-based course design software under development that will present a framework for representing curriculum, particularly in the areas of STEM, and scaffold users through the process of curriculum development.

Research studies show that for $95 \%$ of new faculty members, it takes four to five years, through trial and error (the most common method of gaining expertise in teaching), to deliver effective instruction(Boice, 2000). While there are a number of options available to faculty for receiving instructional development training (i.e., training focused on improving teaching and learning), most share similar format, features, and shortcomings. For example: workshops, courses and seminar series, the most common program structures, 
are often offered at a cost to the institution, department or individual attendee; delivered face-to-face at specified times; and accessible to a restricted number of persons. Even when interest is high, these factors can become obstacles to participation. Our research goal is to develop a framework for outcome-based course design process and translate it into a Semantic Web-based software tool that:

Q guides individual or collaborating users, step-bystep, through an outcome-based education process as they define learning objectives, select content to be covered, develop an instruction and assessment plan, and define the learning environment and context for their course(s).

Q contains a repository of current best pedagogical and assessment practices, and based on selections the user makes when defining the learning objectives of the course, the system will present options for assessment and instruction that align with the type/level of student learning desired.

We have developed the underlying framework for Instructional Module Development System (IMODS) that supports the design of various components of a course such as the learning context, learning objectives, course content, assessments, and instructional techniques of an instructional module(Andhareetal., 2012; Bansal etal., 2015a; Bansal etal., 2015b).Outcome-based education (OBE)(Furman, 1994; Harden etal., 1999)was used as the principal guide for the development of the IMODS framework. The IMOD system will facilitate selfpaced instructional development training while the user creates his/her course design with the added benefits of being free to all who are interested, accessible almost anywhere through a web browser, and at any time that is convenient.

In this paper we present the design and implementation of a repository of current best pedagogical and assessment practices in STEM education and search feature that will present options for assessment and instruction that align with the type/level of student learning desired based on selections the user makes when defining the learning objectives of the course. The paper is organized as follows. In section 2, we present the background for IMODSand related work. In section 3, we present the Pedagogy component of IMODS. In section 4, we present the Assessment component of IMODS. We present our data collection methodology and discussion in section 5 . The paper concludes with a summary and future work section.

\section{Background}

Many of the leaders in faculty development programs have identified facilitation by experts as a key ingredient in increasing the effectiveness of instructional development programs (Felder etal., 2011). For the IMOD system, which will provide professional development with the use of an online tool, expert facilitation is embedded within its design, through the application of a framework that is informed by research in the area of instructional development for STEM disciplines. This framework translates the scholarship into a software platform that supports the development of a rich, meaningful knowledge structure that can be queried to: (1) identify omissions in a course design; (2) identify inconsistencies in the relationships between the elements of the course being designed; (3) identify relevant strategies for instruction and/or assessments; (4) provide just-in-time guidance to the user on the design process.

\section{A. Previous Models of Outcome-Based Course Design}

Outcome-based education (OBE) is an approach where the product defines the process, i.e., the outcomes that specify what students should be able to demonstrate upon leaving the system are defined first, and drive decisions about the content and how it is organized, the educational strategies, the teaching methods, the assessment procedures and the educational environment (Spady, 1988). This is a contrast to the preceding "input-based" model that placed emphasis on the means as opposed to the end of instruction. OBE was used as the principal guide for the development of the IMOD framework. It was chosen for the following reasons: 1) win-for-all solution - OBE is shown to improve student success, provides a structure to educators for designing instruction, and facilitates reporting to external stakeholders in an accountability education climate; 2) it supports the How People Learn framework for designing learning environments (Bransford etal., 2000); 3) growing adoption of outcome-based program accreditation - Accreditation boards such as ABET, have moved to an outcome focused model (what students learned) to assess the quality of programs in Applied Science, Computing, Engineering, and Engineering Technology; 4) 
alignment with other models that are meant to increase innovation in STEM education - OBE dictates the end and not the means thereby allowing innovation in instruction. It also provides an empirical structure to track impact and identify shortcomings.

\section{B. Motivation}

A number of models have been developed to represent the application of OBE in the design of effective courses. Four key models widely discussed in the engineering education literature are: 1) the Effective Course Model by Felder \& Brent (Felder et al., 2011); 2) Integrated Course Design by Fink (Fink, 2003); 3) Understanding by Design Model (Wiggins \& McTighe, 2005); 4) Content Assessment Pedagogy Model by Streveler, Smith, \&Pilotte(Streveler etal., 2012)). All of these models either directly or indirectly identify four main elements that must be tightly aligned when defining a course design, i.e., course objectives, content, assessments, and pedagogy. Therefore, one of the main challenges in adhering to an outcome-based approach is maintaining the alignment between course elements. Inconsistencies in the interrelation of these elements can lead to the overall incoherence of the course.

One approach for achieving alignment among course element is through a "backward-looking" design process where the desired results are identified first, and then assessments are designed to verify that these results have been achieved. The learning experiences and instruction are then formulated around the desired results and the assessments. The use of this approach forms the basis of the Understanding by Design model, and other models also apply it.

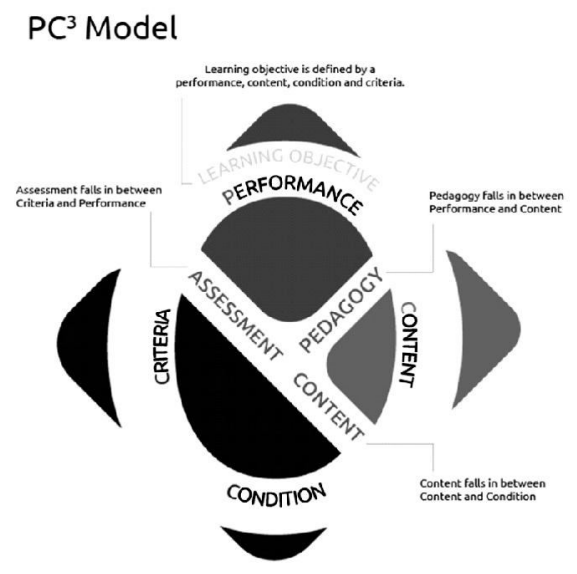

Figure 1: IMODS Framework - PC3 Model
Developing a course design is more than just the implementation of a process. One of the key functions of IMODS is to identify relevant assessment and instructional techniques for the user. To achieve this, IMODS framework must also provide a representation for the knowledge on latest assessment and pedagogical approaches. New data on instructional approaches will be added to the knowledge structure in conformance with the predefined representation. Qualified members of the research team have generated an initial version of a repository of pedagogical and assessment strategies for STEM disciplines attained from an extensive review of vetted literature. As IMODS evolves, new strategies will be added to the system by the community, i.e. the users themselves, and validated by a content administrator before making the knowledge available to everyone.

\section{IMODS Framework}

The IMODS framework adheres strongly to the OBE approach and treats the course objective as the spine of the structure. New constructs (not included in the models previously discussed) are incorporated to add further definition to the objective. The work of Robert Mager(Mager, 1997) informs the IMODS definition of the objective. Mager identifies three defining characteristics of a learning objective: Performance - description of what the learner is expected to do; Conditions - description of conditions under which the performance is expected to occur; and Criterion - a description of the level of competence that must be reached or surpassed. For use in the IMODS framework an additional characteristic was included, i.e., Content - description of the disciplinary knowledge, skill, or behavior to be attained. Resulting IMODS definition of an objective is referred to as PC3 model shown in figure 1.The other course design elements (i.e., Content, Pedagogy, and Assessment) are incorporated into the IMODS framework through interactions with two of the PC3 characteristics.

\section{Pedagogy Component of IMODS}

Pedagogy is the science of specially organized, goal-oriented, and systematic moulding of a human being; the science of content, forms, and methods of upbringing, education, and instruction as defined by the Science of Education, Collins Discovery Encyclopaedia("Science of education | Article about Science of education by The Free Dictionary," n.d.). 
Pedagogy is also referred to as the correct use of instructive strategies. Instruction is an arrangement of the environment to facilitate the acquisition of new knowledge, skills, or attitudes resulting from an individual's external interaction with his or her environment and/or "internal" interaction between new and previously existing information.

The Pedagogy feature of IMODS facilitates identifying and mapping the correct use of the instructional strategies based on the learning objectives that have been defined for an instructional module (i.e., a course). It is used to suggest relevant instructional techniques based on the type of learning and knowledge specified in the learning objective. This feature provides list of various instructional techniques with their description, examples of activities needed to achieve the learning objective, materials required, and references to the research articles that describe the technique. Users can also create new instructional strategies and add them to the repository. Existing instructional strategies can be modified to suit specific needs of a learning objective adhering to the PC3 model. This component generates an instructional plan that allows users to get an overview of the instructional strategies mapped to individual learning objectives.

\section{A. Pedagogy Framework}

Learning domains according to revised Bloom's taxonomy by Anderson \&Krathwohl(Anderson \& Krathwol, 2001) are categorized into Cognitive, Affective, and Psychomotor domains to describe learner performance. Learning domains are further classified under Domain Categories (Remember, Understand, Apply, Analyze, Evaluate, Create). Each Domain Category has performance verbs associated with it. A detailed list of each learning domain and domain category are shown in figure 2 . The revised Bloom's taxonomy has introduced a third dimension for the Cognitive Domain called the Knowledge Dimension as shown in figure 3 . The subtypes of the knowledge dimension are Factual, Conceptual, Procedural and Metacognitive. Factual Knowledge is knowledge of essential facts, terminology, details or elements students must know or be familiar with in order to understand a discipline or solve a problem in it. Conceptual Knowledge is knowledge of classifications, principles, generalizations, theories, models, or structures pertinent to a particular disciplinary area. Procedural Knowledge refers to knowledge of methods of inquiry, very specific or finite skills, algorithms, techniques, and particular methodologies. Metacognitive Knowledge is the awareness of one's own cognition and particular cognitive processes. Each learning objective maps to the verbs associated with each domain category in Bloom's revised taxonomy model. According to the PC3 model, the learning objectives are split into Performance, Content, Condition and Criteria. Performance is mapped to the verb (or action word from domain category) in the Learning domains as defined in revised Bloom's taxonomy (Anderson \& Krathwol, 2001).

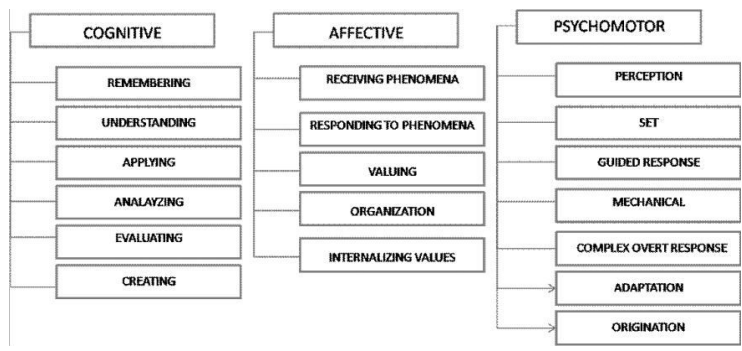

Figure 2: Learning domains and domain categories based on Bloom's taxonomy (Blue boxes indicate Learning Domains and Green boxes indicate Domain Categories)

Course-Pedagogy is linked to the performance and content components of the objective. The types of instructional approaches or learning activities used in a course should correspond to the level of learning expected and the disciplinary knowledge, skills or behaviors to be learned. The content and performance can be used to validate pedagogical choices. Figure 4 shows the Pedagogy framework that is linked to performance and content elements within the PC3 model. The learning objective interface helps identify the learning domain and domain categories that are associated with a learning objective. The knowledge dimension categories are associated with the content topics linked to a learning objective and are obtained from the Content interface of IMODS. Each instructional technique in the IMODS repository is mapped to the domain category and the knowledge dimension of Bloom's taxonomy. These fields are used to match them to corresponding learning objectives with the same domain category and knowledge dimension thereby achieving the alignment between learning objectives and pedagogical (instructional) techniques. 


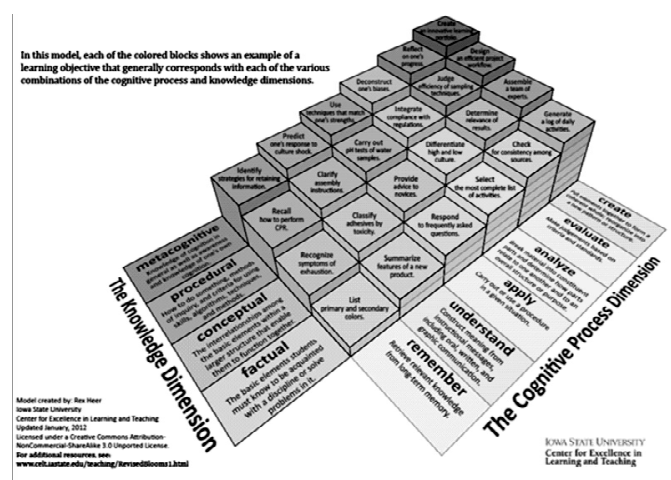

Figure 3: Revision of Bloom's Taxonomy of Educational Objectives (Source: Iowa State University Center for Learning and Teaching)

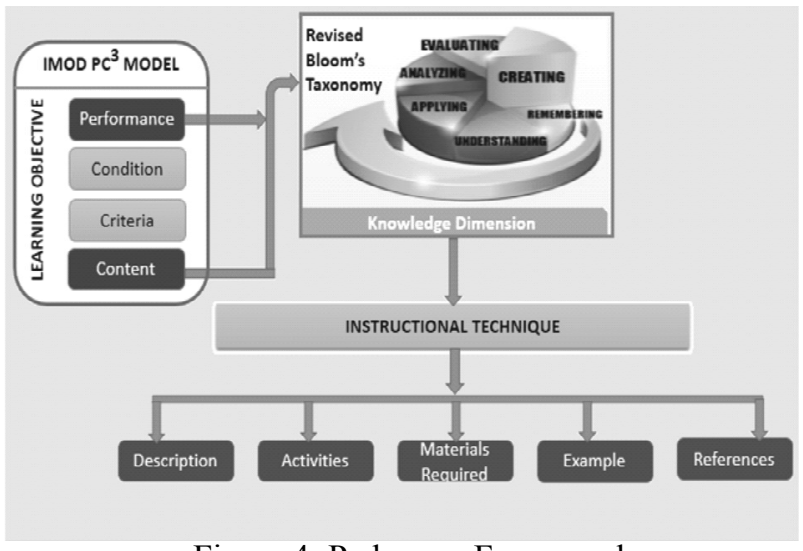

Figure 4: Pedagogy Framework

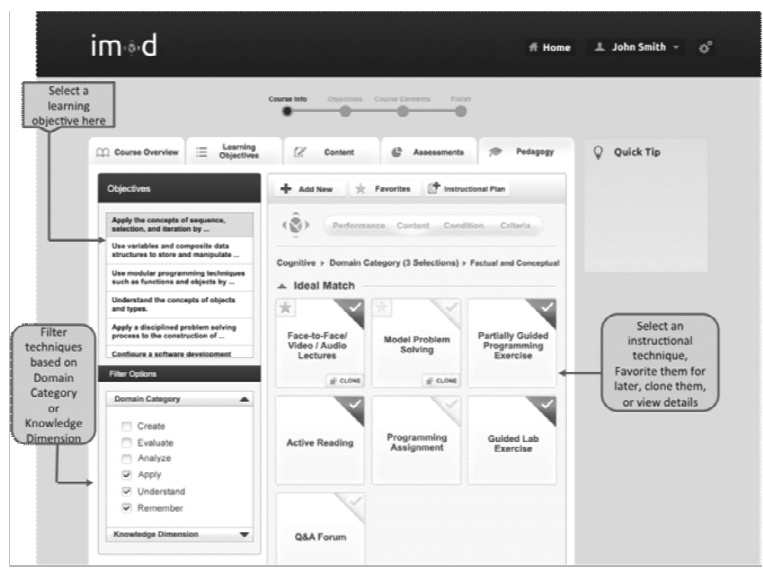

Figure 5: UI screen for Pedagogy feature of IMODS

\section{B. Pedagogy Module Implementation}

A UI mockup of the pedagogy component of IMODS is shown in figure 5 that shows the filter options, search results, and options to assign an instructional technique to a learning objective, copy a technique, favorite a technique, and create new technique. Figure
6 shows the UI mockup for creation of a new instructional technique. The key features of the Pedagogy Module are as follows:

\section{Display Learning Objectives of the course}

口 Search for relevant instructional techniques for a learning objective

( Assign instructional technique to an objective

口 Filter instructional techniques displayed based on domain category \& knowledge dimension filter options

口 Favorite an instructional technique (user level)

૫ Create new instructional techniques

口 Edit existing instructional techniques

口 Clone existing instructional techniques

口 View Instructional Plan

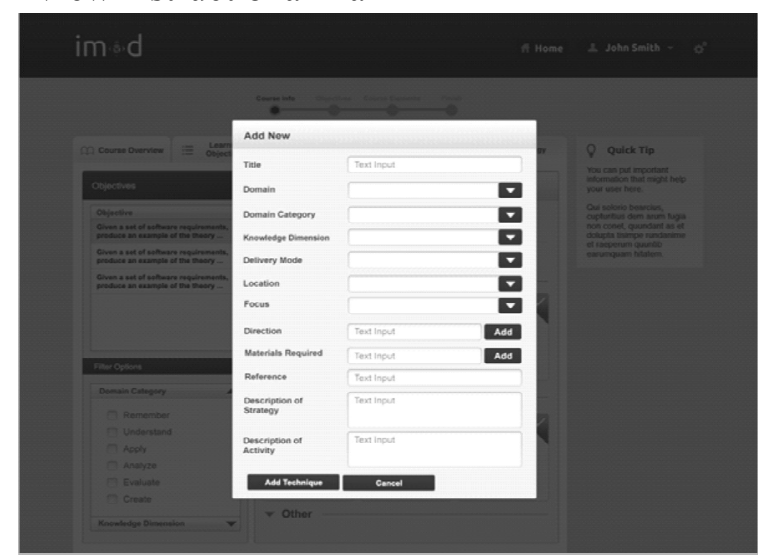

Figure 6: Add new instructional technique UI screen

\section{Assessment Component of IMODS}

Educational assessment determines how well students are learning and is an integral part of the quest for improved education. Assessment is simply the process of collecting information about student learning and performance. Assessments should reveal how well students have learned what was intended while instructional strategies ensure that they learn it. Every assessment, regardless of its purpose, rests on three pillars: Cognition, Observation, and Interpretation (National Research Council, 2001).

( Cognition: A model of how students represent knowledge and develop competence in the subject domain; how they will learn with misconceptions, and difficulty areas identified; define how levels of progression may be classified i.e. Novice to Expert.

口 Observation: Tasks or situations that allow one to 
Q observe students' performance. This means the actual tasks they will perform as part of assessment.

( Interpretation: Method for drawing inferences from the performance evidence thus obtained. Analyze the data collected during the Observation.

\section{A. Assessment Framework}

Course-Assessment is linked to the performance and criteria components of the objective. This affiliation can be used to test the suitability of the assessment strategies since an effective assessment, at the very least, must be able to determine whether the learner's performance constitutes competency. Figure 1 shows a visual representation of the IMODS framework that emphasizes the alignment of course design elements through the PC3 model of an objective and the significance placed on the course design by variables defined in the learning context. Learning objective in the PC3 model is described in terms of Performance, Content, Condition, and Criteria. Criteria are a description of the level of competence that must be reached or surpassed. The assessment criteria are categorized as quality, quantity, speed, and accuracy. Criteria for learning objectives are described in terms of one or more of these categories with a criteria value defined or determined later when the assessment is defined. In the assessment component of IMODS, performance and criteria are used to validate assessment technique choices. Each assessment technique in the IMODS repository is mapped to the domain category and the knowledge dimension of Bloom's taxonomy. These fields are used to match them to corresponding learning objectives with the same domain category and knowledge dimension thereby achieving the alignment between learning objectives and assessment techniques. Figure 7 shows the Assessment framework that is linked to performance and criteria elements within the PC3 model.

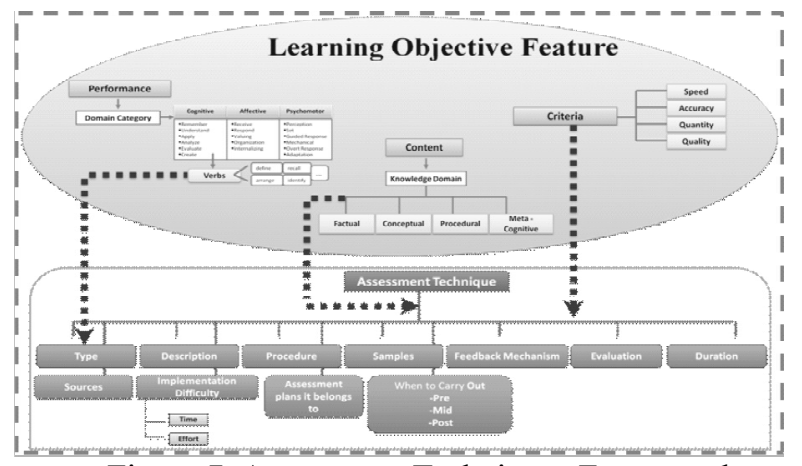

Figure 7: Assessment Techniques Framework

\section{im d}

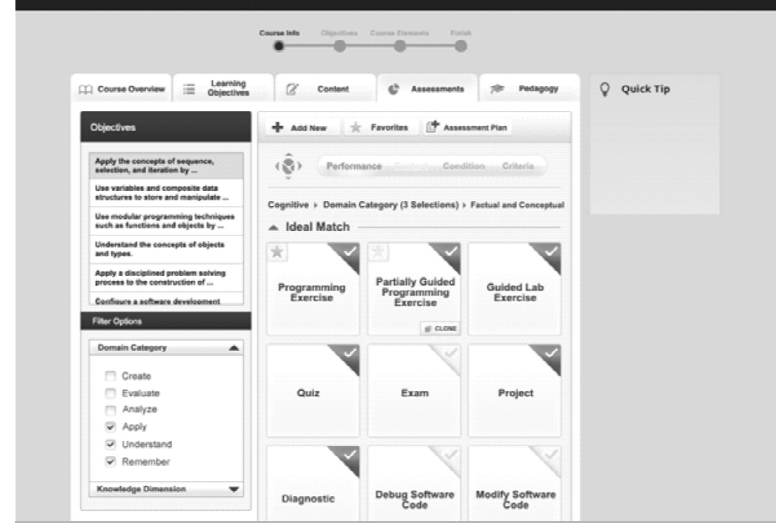

Figure 8: UI screen for Assessments feature of IMODS

\section{B. Assessment Module Implementation}

A UI mockup of the assessment component of IMODS is shown in figure 8 that shows the filter options, search results, and options to assign an assessment technique to a learning objective, copy a technique, favorite a technique, and create a new technique. The key features of the Assessment Module are as follows:

\section{口 Display Learning Objectives of the course}

u Search relevant assessment techniques for an objective

口 Assign assessment technique to a learning objective

口 Filter assessment techniques displayed based on domain category and knowledge dimension filter options

口 Favorite an assessment technique (user level)

口 Create new assessment techniques

口 Edit existing assessment techniques

口 Clone existing assessment techniques

口 View Assessment Plan

Assessment technique is described using these attributes:

u Description: This is a short description of the assessment technique and its key features.

口 Procedure: is a step-by-step instruction of how the assessment is carried out.

( Examples: of how the assessment technique can be applied. Some assessment techniques may also have standard rubrics associated with them. 
( Duration: time taken to execute the technique in class

口 Implementation difficulty level: calculated based on the time and effort required to implement and deliver the assessment technique, students response to the technique, and analysis of data collected from the assessment technique. It is indicated in terms of low, medium, or high.

u When to carry out: specifies the time when it is best suited for and indicated in terms of Pre, Mid, or Post.

" Feedback mechanism: provides list of various feedback strategies that will best suit a particular assessment. It is indicated in terms of in-person, online, or both.

口 References: provides the source or research article where the technique has been described.

\section{Data Collection Methodology}

Our methodology for data collection and to populate the repository with latest instructional and assessment techniques involved the following tasks:

( Conducting extensive literature review of educational models, instructional and assessment techniques for inclusion in the repository.

口 Conducting focus groups with ASU faculty with expertise in instructional design, assessment and pedagogical practices, librarian who works with educational literature, and instructional designers at ASU Online.

口 Various search strategies to search various research databases for articles reporting on latest instructional or pedagogical techniques.

The above tasks informed the design and layout of our repository and the development of metadata structure to store the techniques. For all techniques populated into the repository the learning domain, domain category, and knowledge dimension that they fit into were also coded. The data collected so far is from the following sources that are applicable for STEM education:

口 American Society for Civil Engineers (ASCE)

口 American Society for Mechanical Engineers (ASME)

( American Society for Engineering Education (ASEE)

口 IEEE Digital Xplore
( ACM Digital Library

૫ "Collaborative Learning Techniques" by Elizabeth F. Barkley, K.Patricia Cross and Claire Howell Major (1st edition). California: Jossey-Bass, 2005.

口 "Student engagement techniques" by Elizabeth F. Barkley(1st edition). California: Jossey-Bass, 2010

口 "Classroom Assessment Techniques" by Thomas Angelo,Patricia Cross (2nd ed.) California: JosseyBass.

Assessment techniques collected include both formative and summative assessments. The goal of formative assessment is to helpstudents identify their strengths andweaknesses and target areas that need work, help faculty recognize where students arestruggling and address problemsimmediately. Examples offormative assessments included in our repository are background knowledge probe, pro \& con grid, student generated test questions, minute paper, muddiest point, etc. The goal of summative assessments is to evaluate student learning at the end of an instructional unit by comparing it against some standard or benchmark. Example summative assessments included in our repository are final exams, capstone projects, practicum or internship, midterm exam, final project, paper presentations, senior recital, etc.

Instructional techniques collected includes examples such as partially guided programming exercise, structured problem solving, think aloud protocol, pair problem solving, pair programming, jigsaw learning activity, in-class portfolio, structured problem solving, critical debate, three-step interview, round table discussion, case study, dialogue journals, collaborative writing, role play, game-based learning, project-based learning, etc.

\section{Conclusions and Future Work}

The development and testing of the semantic webbased IMODS tool is underway. The data collection for building the repository is underway through an extensive literature review process. The initial sets of techniques identified for the repository have been reported in this paper. Our research team is continuing to identify more techniques and populating them into the database. Thesources for the data collected have been described in section 5. We plan to conduct usability testing of the software and evaluation of the outcome-based course design process and repository of current best practices in instructional and 
assessment techniques using user interviews and other usability testing methods. Semantic web technologies facilitate: the organization of knowledge into conceptual spaces, based on their meanings; extraction of new knowledge via querying; and maintenance of knowledge by checking for inconsistencies. These technologies are being used in IMODS development to support the construction of an advanced knowledge management system (Antoniou \& Van Harmelen, 2004; Shadbolt etal., 2006).

\section{Acknowledgement}

The authors gratefully acknowledge the support for this project under the NSF Transforming Undergraduate Education in STEM (TUES) program Award No. DUE-1246139. The authors acknowledge the efforts of the student development and testing team who have contributed towards implementation of the tool.

\section{References}

Anderson, L. W., \& Krathwol, D. R. (2001). A taxonomy for learning, teaching and assessing: A revision of Bloom's Taxonomy of educational objectives. New York Longman.

Andhare, K., Dalrymple, O., \& Bansal, S. (2012). Learning Objectives Feature for Instructional Module Development System. Presented at the PSW American Society for Engineering Education Conference, San Luis Obispo, CA.

Antoniou, G., \& Van Harmelen, F. (2004). A semantic web primer. MIT Press.

Bansal, S., Bansal, A., \& Dalrymple, O. (2015a). Outcome-based Education Model for Computer Science Education. Journal of Engineering Education Transformations, 28(2\&3), 113-121.

Bansal, S., Dalrymple, O., \& Gaffar, A. (2015b). Design, Development, and Implementation of the Instructional Module Development System (IMODS). In American Society for Engineering Education Annual Conference (ASEE). Indianapolis, IN.

Boice, R. (2000). Advice for new faculty members. Allyn \& Bacon.

Bransford, J. D., Brown, A. L., \& Cocking, R. R. (2000). How people learn. National Academy Press Washington, DC. Retrieved from http://www.csun.edu/ SB4310/HowPeopleLearn.pd

\section{$\mathrm{f}$}

Felder, R. M., Brent, R., \& Prince, M. J. (2011). Engineering Instructional Development: Programs, Best Practices, and Recommendations. Journal of Engineering Education, 100(1), 89-122. http://doi.org/Article

Fink, L. D. (2003). Creating significant learning experiences: An integrated approach to designing college courses. San Francisco: Jossey-Bass.

Furman, G. C. (1994). Outcome-Based Education and Accountability. Education \& Urban Soc., 26(4), 417437.

Harden, R. M., Crosby, J. R., \& Davis, M. H. (1999). AMEE Guide No. 14. Outcome-Based Education: Part 1--An Introduction to Outcome-Based Education. Medical Teacher, 21(1), 7-14.

Mager, R. F. (1997). Preparing Instructional Objectives: A critical tool in the development of effective instruction 3rd edition. The Center for Effective Performance, Inc.

National Research Council. (2001). Knowing What Students Know: The Science and Design of Educational Assessment. Washington, DC: The National Academies Press. Retrieved from http://www.nap.edu/catalog/10019

Science of education $\mid$ Article about Science of education by The Free Dictionary. (n.d.). Retrieved $\mathrm{O}$ c t o b e r 5, $2015, \quad$ f r o m http://encyclopedia2.thefreedictionary.com/Scienceo feducation

Shadbolt, N., Hall, W., Berners-Lee, T. (2006). Semantic web revisited. Intelligent Systems, IEEE, 21(3), 96-101.

Spady, W. G. (1988). Organizing for Results: The Basis of Authentic Restructuring and Reform. Educational Leadership, 46(2), 4-8.

Streveler, R. A., Smith, K. A., \& Pilotte, M. (2012). Aligning Course Content, Assessment, and Delivery: Creating a Context for Outcome-Based Education. Outcome-Based Education and Engineering Curriculum: Evaluation, Assessment and Accreditation. Hershey, Pennsylvania: IGI Global.

Wiggins, G. P., \& McTighe, J. (2005). Understanding by design. Association for Supervision \& Curriculum Development. 